\title{
Cyanotoxins: The Most Powerful Known Natural Poisons
}

\section{Indranil Chatterjee*}

Department of Pharmaceutical Biotechnology, Calcutta Institute of Pharmaceutical Technology and Allied Health Sciences, Howrah, West Bengal, India

*Corresponding Author: Indranil Chatterjee, Department of Pharmaceutical Biotechnology, Calcutta Institute of Pharmaceutical Technology and Allied Health Sciences, Howrah, West Bengal, India.

Received: July 04, 2019; Published: September 30, 2019

DOI: 10.31080/ASMI.2019.02.0387

Cyanotoxins are toxins made by microorganism referred to as true bacteria (also called blue-green algae). True bacteria are found nearly everywhere, but considerably in lakes and inside the ocean where, at a lower place high concentration of phosphorus conditions, they reproduce exponentially to form blooms. Blooming eubacteria can end up cyanotoxins in such concentrations that they poison and even kill animals and humans.

Cyanotoxins will even accumulate in several animals like fish and shellfish, and cause poisonings like shellfish poisoning. Among cyanotoxins are a number of the foremost powerful natural poisons familiar, as well as poisons which may cause speedy death by metabolic process failure.

[1] The toxins contain potent neurotoxins, hepatotoxins, cytotoxins, and endotoxins. Despite the similarity in name but not cyanides. Long exposure to these bacteria may cause in gastrointestinal, allergic rhinitis symptoms or pruritic skin rashes [2]. Exposure to the eubacteria toxin BMAA is also associate degree environmental reason for neurodegenerative diseases like ALS, Parkinson's unwellness and Alzheimer's unwellness [3]. There's was an associate degree interest within the military potential of biological neurotoxins with cyanotoxins, that have increasing significance as potential candidates for weaponisation." [4].

The first report of cyanobacteria which shows deadly effects fad appeared in Nature Journal in 1878. Patron saint Francis delineated the protectant bloom he ascertained within the water of the Murray in Australia, as "a thick scum like inexperienced paint, some 2 to 6 inches thick." life that drank the water died chop-chop and really [5]. Fresh environments shows the most reportable incidents of poisoning by microalgal toxins that have occurred, and become a lot of common widespread. Thousands of ducks and geese died drinking contaminated water within the western us which shows a common example of poisoning [6] In 2010, marine mammals were reportable to possess died from ingesting cyanotoxins [7].

Cyanotoxins are created by eubacteria, a phylum of bacterium that get their energy through chemical change. Moreover, Cyan comes from the Greek kúavoৎ meaning "a blueness substance",
[8] and typically indicates a variety of colours within the blue/green vary of the spectrum. Eubacteria are unremarkably stated as true bacteria and they were thought of as a kind of protoctist, which were introduced intrinsically in older textbooks. But these sources tend to treat as outdated;

[9] they're currently thought-about to be a lot of closely associated with bacterium, [10] and therefore the term for true protectant restricts to eukaryotic organisms [11]. Eubacteria have chemical action and contain photosynthetic pigments, indicating as blue.

Cyanobacteria are found widely in oceans, lakes, rivers as well as in shores. They are mainly found in Arctic and Antarctic lakes, [12] hot springs [13] and waste matter treatment plants [14]. They inhabits with the fur of polar bears, to convey a green tinge [15]. These bacteria possess potent toxins, however they turn out useful bioactive compounds, together with substances such as antitumor, antiviral, anticancer, antibiotic, antifungal activity, UV protectants and specific inhibitors of enzymes [16,17]. They are involved as red tides or harmful blooms. Lakes and oceans contain several onecelled organisms referred to as plant life. Under certain bound conditions, significantly nutrient concentrations are higher in these organisms which reproduces exponentially. The ensuing dense swarm of plant life is termed an protectant bloom; these can cover vast distances and might be seen in satellite views. Individual plant life seldom live quite many days, however blooms will last weeks $[18,19]$.

Generally, these blooms are harmless, however they're referred as harmful blooms, or HABs. HABs contain toxins or pathogens which might even be fatal to humans [19]. In marine environments, HABs are mainly caused by dinoflagellates, [20] alternative species of alga taxa and cause HABs (diatoms, flagellates, haptophytes and raphidophytes) [21]. Marine mastigophore species are typically deadly, however fresh species don't seem to be better-known to be deadly. Neither are diatoms better-known to be deadly, a minimum of to humans [22]. As with alternative cyanotoxins, microcyst ins were named once the primary organism discovered to supply them, Microcystis aeruginosa. but it had been later found alternative class genera additionally created them [23]. There are 60 proverbial variants of microcystin, and several others in a bloom. 
The abundantly reported variant: microcystin-LR, commercially on the chemical market [23]. Blooms with microcystin are widely seen in ecosystems with freshwater environments [24]. Microcystis are cyclic peptides and might be terribly virulent for plants and animals as well as humans. They mainly get biologically accumulated within the liver of fish, hepatopancreas of mussels, and also in creature. They are hepatotoxic and might leads to serious harm to the Human liver [23]. They're like the nodularins (below), along the microcystins and nodularins account for many of the virulent class blooms in salt waters [17].

A wide variety of oceans were poisoned by microcystin in the year 2010. Marine bivalves were the seemingly supply of toxic shellfish poisoning, indicating confirmed example of a marine vertebrate dying from ingesting a cyanotoxin [7]. Non-proteinogenic organic compound: beta-Methylamino-L-alanine (BMAA) is liberated by these organisms in marine, freshwater, brackish, and terrestrial environments $[25,26]$. The mechanisms of BMAA toxicity on nerve cell cells is being investigated by the researchers all over the globe and analysis suggests each acute, chronic mechanisms of toxicity $[27,28]$. BMAA is being investigated as a possible environmental risk issue for neurodegenerative diseases, together with ALS, Parkinson's unwellness and Alzheimer's disease [29].

\section{Bibliography}

1. Stewart I., et al. "Cyanobacterial poisoning in livestock, wild mammals and birds - an overview". Advances in Experimental Medicine and Biology 619 (2008): 613-637.

2. Stewart I., et al. "Recreational and occupational field exposure to freshwater cyanobacteria - a review of anecdotal and case reports, epidemiological studies and the challenges for epidemiologic assessment". Environmental Health 5.1 (2006): 6.

3. Holtcamp W. "The emerging science of BMAA: do cyanobacteria contribute to neurodegenerative disease?". Environmental Health Perspectives 120.3 (2012): a110-a116.

4. Dixit A., et al. "Military potential of biological neurotoxins". Toxin Reviews 24.2 (2005): 175-207.

5. Francis G. “Poisonous Australian Lake”. Nature 18.444 (1878): 11-12.

6. Anatoxin Neil Edwards, University of Sussex at Brighton. (1999).

7. Miller MA., et al. "Evidence for a Novel Marine Harmful Algal Bloom: Cyanotoxin (Microcystin) Transfer from Land to Sea Otters". PLoS ONE 5.9 (2010): e12576.

8. Henry George Liddell, Robert Scott, A Greek-English Lexicon, on Perseus.
9. Nabors and Murray W. "Introduction to Botany". San Francisco, CA: Pearson Education, Inc (2004).

10. Ed Guiry., et al. "New Survey of Clare Island Volume 6: The Freshwater and Terrestrial Algae". Royal Irish Academy (2007).

11. Allaby M."Algae". The Concise Dictionary of Botany. Oxford: Oxford University Press (1992).

12. Skulberg OM. "Terrestrial and limnic algae and cyanobacteria". In: A Catalogue of Svalvard Plants, Fungi, Algae and Cyanobacteria, Part 9, a Elvebakk and P Prestud (eds.) Norsk Polarinstitutt Skrifter 198 (1996): 383-395.

13. Castenholz RA. "Ecology of blue-green algae in hotsprings". In: The Biology of Blue-green algae. NG Carr and BA Whitton (1973): 379-414.

14. Vasconcelos VM and Pereira E. "Cyanobacteria diversity and toxicity in a Wastewater Treatment Plant (Portugal)". Water Research 35.5 (2001): 1354-1357.

15. Gerald Karp. "Cell and Molecular Biology: Concepts and Experiments". John Wiley and Sons (2009): 14.

16. Herrero A and Flores E. "The Cyanobacteria: Molecular Biology, Genomics and Evolution". Caister Academic Press (2008).

17. Sivonen K and Jones G. "Cyanobacterial Toxins" Archived 2007-01-24 at the Wayback Machine In Toxic Cyanobacteria in Water. Chorus I and Bartram J (eds) (1999): 41-111.

18. Lindsey R and Scott M. What are phytoplankton NASA Earth Observatory (2010).

19. Harmful algal blooms event response NOAA, Center of Excellence for Great Lakes and Human Health (2014).

20. Stewart I and Falconer IR. "Cyanobacteria and cyanobacterial toxins" in Oceans and human health: risks and remedies from the seas, Eds: Walsh PJ, Smith SL and Fleming LE. Academic Press (2008): 271-296.

21. Moestrup O., et al. "IOC-UNESCO Taxonomic Reference List of Harmful Micro Algae (HABs)" (2011).

22. Vasconcelos V. "Eutrophication, toxic cyanobacteria and cyanotoxins: when ecosystems cry for help". Limnetica 25.1-2 (2006): 425-432.

23. Ingrid Chorus and Jamie Bartram. "Toxic Cyanobacteria in Water: A Guide to their Public Health Consequences, Monitoring and Management". Limnology and Oceanography Taylor and Francis 45 (1999): 1212. 
24. Pelaez Miguel., et al. "Xenobiotics in the Urban Water Cycle". Environmental Pollution 16 (2010): 101-127.

25. Cox PA., et al. "Diverse taxa of cyanobacteria produce b-N-methylamino-L-alanine, a neurotoxic amino acid". Proceedings of the National Academy of Sciences 102.14 (2005): 5074-5078.

26. Esterhuizen $M$ and Downing TG. " $\beta$ - $N$-methylamino-L-alanine (BMAA) in novel South African cyanobacterial isolates". Ecotoxicology and Environmental Safety 71.2 (2008): 309-313.

27. Weiss JH., et al. "Neurotoxicity of $\beta$-N-methylamino-L-alanine (BMAA) and $\beta$-N-oxalylamino-L-alanine (BOAA) on cultured cortical neurons". Brain Research 497.1 (1989): 64-71.

28. Lobner D., et al. " $\beta$-N-methylamino-L-alanine enhances neurotoxicity through multiple mechanisms". Neurobiology of Disease 25.2 (2007): 360-366.

29. Cox PA., et al. "Dietary exposure to an environmental toxin triggers neurofibrillary tangles and amyloid deposits in the brain". Proceedings of the Royal Society B 283.1823 (2016): 20152397.

\section{Volume 2 Issue 10 October 2019}

(c) All rights are reserved by Indranil Chatterjee. 